\title{
Suicide terrorist mobilization: Familial ties and sibling socialization
}

\author{
Anonymized authors
}

October 1, 2019

\begin{abstract}
Previous research has attributed the motivations of suicide terrorists to religious fervor, political engagement, and organizational strategic goals, among others. The motivations of suicide terrorists, however, are often related to local and familial dynamics; specifically, combatants' primary socialization on norms related to violence. To better understand suicide terrorism, we use a data set of 2,923 individual fighter-level observations of combatants for the Islamic State. These data include individual demographic data and the fighter's role for the Islamic State; including if they volunteered to be a suicide fighter. Through these data we test several extant theories of suicide terrorist mobilization (i.e., ideational or economic incentives) compared to the effect of primary socialization. We find that combatants who have a sibling that volunteered to be a suicide terrorist are approximately 10 times more likely to volunteer to be a suicide fighter. This was the largest effect on mobilization compared to other theories.
\end{abstract}

Word count: 8,311 


\section{Introduction}

In March of 2016, Ibrahim and Khalid el Bakraoui helped carry the worst terrorist attack in Belgian history and most devastating attack in Europe since the 2005 London train bombings (Vinograd and M'Kele 2016; Burke July 9, 2005). Ibrahim, the older brother, first detonated a suicide bomb outside Zaventem airport terminal in Brussels. Shortly thereafter, Khalid detonated a suicide bomb in a nearby metro station. In total, 35 people were killed and over 300 were injured. While the magnitude of this attack was unprecedented for Belgium, such terrorist attacks have become increasingly frequent internationally. Over the last decade, countries have faced increased levels of terrorism driven in part by the Islamic State and its affiliates, but also from white nationalist groups. Since 2008, Islamic State attacks have accounted for 25 percent of suicide terrorism casualties worldwide in over 20 states. Suicide terrorism is especially problematic because it is approximately five times as deadly as general terrorist attacks (Global Terrorist Database 2018).

Despite widespread recognition among policymakers and academics that suicide terrorism is devastating to civilian populations, researchers remain divided on the causes and motivation of suicide terrorists. Scholars have attributed suicide terrorism to a wide range of potential causes, including individual pathologies of the attackers (Pedahzur, Perliger and Weinberg 2003), environmental conditions (Gunaratna 2004; Khashan 2003), and organizational strategic goals (Pape 2003, 2006; Piazza 2008; Bloom 2004; Asal et al. 2009).

Likewise, the specific cause of the Bakraoui brothers' radicalization remains obscure. Their parents were Moroccan immigrants to Belgium, with both spending their childhood in the Laeken neighborhood in Brussels. Both brothers had a criminal record, with Ibrahim serving prison time for attempted robbery and Khalid serving prison time for several robberies and carjackings. Belgian law enforcement believes that while in prison the brothers became radicalized (Blaise et al. March 24, 2016). Belgian prisons are notorious breeding grounds for Islamic State radicalization (Temple-Raston March 13, 2016). However, the exact mechanism through which someone becomes radicalized within prison remains unclear. Indeed, there are several potential causal pathways to radicalization. For example, the prison population may be more violent and less educated than the general population, which helps lead to radicalization. Alternatively, the act of incarceration may contribute to feelings of social exclusion and isolation, which in turn lead to radicalization. Or, the lost 
income from serving time in prison may make joining the Islamic State more financially appealing. If correct, these explanations should also apply to Islamic State recruits who were not previously incarcerated and are typically from different states. Yet, based on leaked internal Islamic State documents less than 1 percent of Islamic State recruits who fought in Syria between 2010 and 2014 stated they had been previously incarcerated or had black market professions before joining the Islamic State. In fact, Islamic State combatants have higher mean years of education and lower rates of unemployment than male populations in their respective home countries (Edgerton 2019). Further, these combatants are from a diverse set of regions, states, and cities; with fighters from over 60 different countries spanning five continents.

In this paper, we examine an alternative causal explanation for terrorist mobilization; the role of socialization on violent terrorist behavior. In particular, we ask how familial ties affect subsequent violent behavior (i.e., violence committed on behalf of a terrorist organization)? We argue that socialization plays a crucial role for terrorist mobilization, especially through familial networks. Indeed, several major terrorist organizations have leadership positions that are filled by members of the same family, including al Qaeda, the Islamic State, and Boko Haram (Callimachi 2019; El Deeb July 4, 2018; Zenn 2014). The importance of familial ties even extends to lower level foot soldiers in organizations. The Islamic State's propaganda magazine, Dabiq, discussed the Bakraoui brothers' radicalization, noting the important role they played in the Belgian attacks:

All preparations for the raids in Paris and Brussels started with him [Khalid] and his older brother Ibrahim. These two brothers gathered the weapons and the explosives (Spier 2018; Colas 2017).

In addition to the Bakraoui brothers, some notable examples include the Tsarnaev brothers in the 2013 Boston Marathon attacks, three sets of brothers that were part of the terrorist team involved in the September $11^{\text {th }}$ terrorist attacks, the French anarchist brothers Ėmile and Fortunè Henry, and the extremist Jewish Amir brothers who assassinated Israeli Prime Minister Yitzhak Rabin (Gertz 2016; Yardley, Callimachi and Shane March 24, 2016).

A rich body of research in psychology and sociology has demonstrated the importance of socialization on the behavior of individuals. Specifically, people learn what is appropriate from observing their family members and peers. In turn, some psychologists and sociologists posit that violent and deviant behavior is often learned through primary socialization (i.e., learning from family members and close friends). For 
example, if an individual's family and friends belong to a gang, they may become involved in gang activity through interaction with them (Sutherland and Cressey 1978).

In the present paper, we argue that suicide terrorist mobilization is similarly caused by primary socialization. Indeed, if participation in terrorism is similar to other criminal and politically violent behavior, we must recognize that suicide terrorist versus non-suicide terrorist mobilization is partially contingent on social interactions. In the case of the Islamic State, volunteering to be a suicide terrorist is learned through sibling interaction. We find that if a combatant has a sibling who volunteered to be a suicide fighter, they are over 10 times more likely to also volunteer to be a suicide terrorist all else being equal. In addition to this finding, we make two other contributions to the literature on suicide terrorist mobilization. First, we test alternative existing individual level theories for suicide terrorist mobilization including the effect of education, employment, religious fervor, and social marginalization (i.e., is the combatant married or do they have children). And second, we test several environmental mechanisms for suicide terrorist mobilization, including the effect of state governance, wealth, and colonial history. At the individual level, we find that suicide terrorists are not motivated by religious fervor. At the environmental level, we find that suicide terrorists are from states with a colonial history, which suggests they may be partially motivated by political grievances.

In the analysis, the effect of socialization is operationalized by whether a fighter's sibling volunteered to be a suicide terrorist. If a combatant's sibling volunteered to be a suicide terrorist, we infer the sibling is introducing and normalizing this type of violence within their family. In this way, the process of suicide terrorist mobilization is analogous to other forms of socialization for deviant behavior. In addition to testing the effect of sibling socialization, we also test several extant theories of suicide terrorist mobilization, including the individual characteristics of the combatant's wealth, ideational motivations, familial status, education, and environmental causes, such as the state polity, colonial history, and wealth of the combatant's home country. The environmental causes included in the analysis are drawn from previous studies of suicide terrorist mobilization which primarily model suicide terrorism as a function of a state's characteristics (e.g., suicide terrorists are mobilized if their state was colonized by a European power). 


\section{Familial socialization and political violence}

\subsection{Socialization and familial ties}

The importance of socialization on criminal and deviant behavior is well established in the extant sociology research. In this literature, criminal behavior is often found to be learned through socialization, especially through familial and friendship networks (Matsueda 2006; Burgess and Akers 1966; Berg and Huebner 2011; Agnew 2005; Sutherland and Cressey 1978). Familial socialization is especially important for the development of an individual's ideology, norms, and behaviors (Bales and Parsons 2014; Bandura and Walters 1977). Within a family unit and friend groups, these values are learned and reinforced through individual interactions. Often, scholars have found a strong association between substance abuse (McCabe et al. 2005; Dull 1983), participation in violence (DeLisi, Berg and Hochstetler 2004; Stretesky and Pogrebin 2007; Kissner and Pyrooz 2009), and antisocial behavior (Rosenbaum and O'Leary 1981) within families and friend groups.

Research on the micro-processes of civil war and conflict also offer explanations for how politically violent behavior is contingent on personal relations and local power structures (Kalyvas 2006; Bax 1995; Stammers 2017; Atran 2011; Fujii 2008). Gertz (2016) expands on these theories and argues that politically violent behavior is similar to other criminally deviant behavior. In her piece, Gertz finds that perpetrators of extreme violence during the 1994 genocide in Rwanda were driven in part by their siblings also engaging in extreme violence. Other scholars have noted the importance of socialization on political engagement, with researchers finding that exposure to violence increases support for terrorism and genocide (McCauley and Moskalenko 2008; Fujii 2004), exacerbates in- and out-group divisions (Lupu and Peisakhin 2017), increases the rate of homicide (Ember and Ember 1994), and drives democratic participation (Blattman 2009; Wood and Jean $2003)$.

In the present piece, we build on this work by introducing the first transnational analysis of the effect of familial socialization on suicide terrorist mobilization. In turn, we posit that suicide terrorist mobilization is similar to other deviant behavior in that it brought on by primary socialization. Specifically, people learn

what is acceptable behavior through observing each other. In the case of suicide terrorism, mobilization is therefore dependent on the norms, political views, and interactions within an individual's social network; 
particularly if a combatant's sibling volunteered to be a suicide terrorist. Thus, existing theories that suicide terrorists are motivated by ideational or economic incentives are insufficient for explaining this phenomenon.

\subsection{Terrorist mobilization}

From a rational perspective, volunteering to be a suicide terrorist is puzzling because the cost of being a suicide terrorist is totally borne by the participant, while the terrorist organization receives all the benefits. Previous research has argued that suicide terrorists are motivated by individual characteristics (Crenshaw 2000; Pedahzur, Perliger and Weinberg 2003), environmental conditions (Piazza 2006; Choi and Piazza 2016; Okafor and Piesse 2018; Rüegger 2019), and the strategic goals of the terrorist organization (Pape 2003, 2006; Krieger and Meierrieks 2011). Political science research on suicide terrorism often uses the aggregate count of suicide terrorist attacks at the state level as the outcome of interest. This allows researchers to model the count of suicide terrorist events as a function of a state's attributes; such as if the state is democratic or violates human rights. Some researchers have used this process to infer individual motivations from state level outcomes. Interview research on suicide terrorism has also yielded several theories on mobilization; including that combatants are socially isolated (Kruglanski et al. 2009), religious extremists (Khashan 2003), politically aggrieved actors (Berrebi 2007; Benmelech, Berrebi and Klor 2012; Abadie 2006; Merari 2010), have strong in-group identity and out-group animosity (Schwartz, Dunkel and Waterman 2009; Pedahzur, Perliger and Weinberg 2003), or are driven by individual pathologies (Crenshaw 2000; Horgan 2008).

There are three notable limitations posed by studying suicide terrorism through state level outcomes or by interviewing combatants. First, aggregating suicide terrorist events to the state level can prevent researchers from understanding subnational dynamics which contribute to suicide terrorist mobilization (Ashworth et al. 2008). This issue is especially pronounced in studies of suicide terrorism because suicide terrorists are also mobilized by familial and social relations. Second, interview research on suicide terrorism relies on people that have not successfully carried out the attack. This introduces literal survivorship bias into the analysis. And third, there is wide overlap between the motivations of suicide terrorist and non-suicide terrorist mobilization. Thus, if a researcher does not control for general terrorist mobilization in their analysis, they may actually make inferences about terrorist mobilization, which is related, but distinct from suicide terrorism. 


\section{Data}

\subsection{Description}

To test our argument, we leverage a unique data set of 4,237 leaked Islamic State job applications. These documents were provided to the research team by a journalist who covers the Islamic State. The documents were given to the journalist from a former Islamic State combatant. In March 2016, the disaffected Islamic State combatant returned to Germany from Syria after stealing several internal Islamic State documents. The former combatant gave the stolen documents to several news organizations and intelligence agencies. Among the documents were the "job applications" of Islamic State volunteers who had traveled to Syria to join the Islamic State between 2010 and 2014. Out of 4,237 applications, only 2,923 unique applications contained the home country, combatant's first and last names, and their mother's name. These variables are crucial for identifying siblings among the combatant data. In addition to the aforementioned variables, the applications also contained the fighters' previous occupations, educational attainment, date of birth, knowledge of Sharia, marital status, number of children, and the combatant's requested role for the Islamic State (MacAskill 2016). In the applications, Islamic State volunteers could request to be a soldier, administrative worker, suicide bomber, or Inghimasi. Inghimasi combatants are tasked with infiltrating enemy lines and attacking from within, with the understanding that they will be killed during their mission. As such, Inghimasi soldiers are occasionally equipped with a suicide bomb vest so they can inflict maximum damage to the opposing forces (Barfi 2016). Figure 1 displays descriptive counts for the Islamic State fighters' demographic information.

A team of coders translated the documents for analysis, with the open entries recoded into categorical variables (e.g., what was the occupation category or educational level of the combatants). Each coder sampled a subset of the other coders work to ensure consistent coding practices. After matching siblings in the data, the identifiable information of the combatants was stripped from the aggregated data. The data collection and cleaning is supported by the research teams' Institutional Review Board, with all members undergoing appropriate ethics training.

Although this is the first data set to explore the importance of familial ties on suicide terrorist mobilization, there are several other studies which have used the leaked Islamic State applications in their analysis to study 


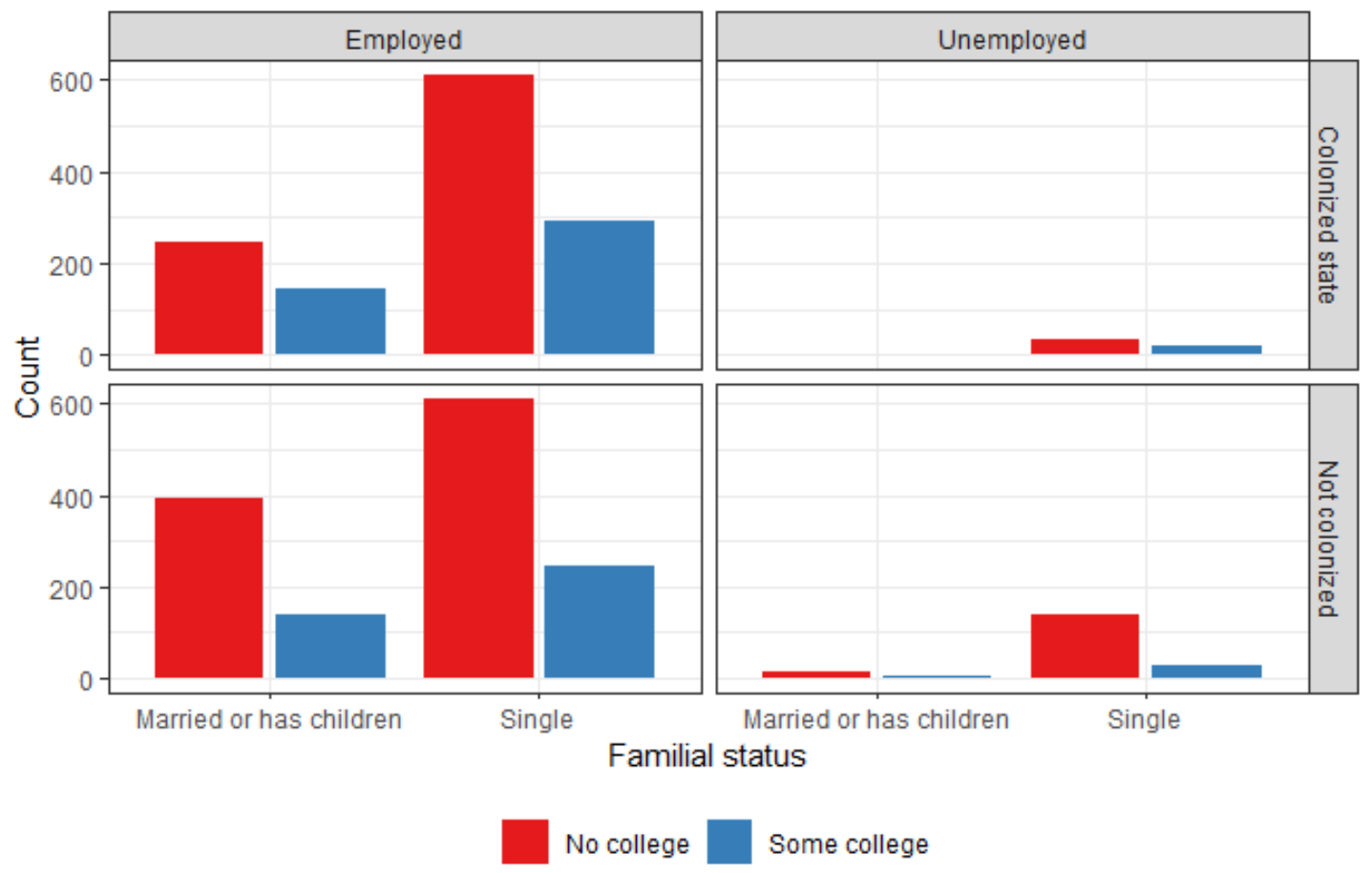

Figure 1: The count of Islamic State fighters by education, previous employment, familial status, and the colonial history of their home country.

combatant mobilization, including research from the World Bank (Jelil et al. 2018), West Point (Omar and Engel 2018), and King's College (bin Khaled Al-Saud 2019), among others (Edgerton 2019). ${ }^{1}$ In their report, Jelil et al. (2018) use suicide terrorist as an independent variable to predict knowledge of Sharia. However, this is the first analysis with these data to explicitly study suicide terrorism as the primary outcome of interest.

\subsection{Sibling socialization and dependent variable}

To identify siblings in the data, the research team used the last name, mother last name, first name, and home state of the combatants. In total, there were over 220 million unique last name, mom last name, and home country potential combinations with over 6 billion unique combatant pairs in the data. Because the combatants' names and demographic information were manually entered by the Islamic State upon entering Syria, there is wide variation in name spelling. To address spelling errors, the research team used the soundex and Levenshtein distance to identify potential siblings in the data using the names of combatants. Soundex

\footnotetext{
${ }^{1}$ In their analysis, West Point confirmed the veracity of 98 percent of the leaked applications (Omar and Engel 2018).
} 


\begin{tabular}{|c|c|c|c|c|c|c|}
\hline First name Last name & Home state & Mom Name & & & & \\
\hline Anderson & USA & Susan Smith & & & & \\
\hline Potential match names & Home state & Name soundex & Name Levenshtein & Mom name & Mom soundex & Mom Levenshtein \\
\hline$\rightarrow$ Paul Anderson & USA & A536 & 0 & Susan Smith & $\mathrm{S} 250$ & 0 \\
\hline$\longrightarrow$ Greg Anderson & Cananda & A536 & 0 & Susan Smith & S250 & 0 \\
\hline$\rightarrow$ Howie Andy & USA & A536 & 8 & Susan Smith & $\mathrm{S} 250$ & 0 \\
\hline$\longrightarrow$ Larry Anderson & USA & A536 & 0 & Susan Small & $\mathrm{S} 250$ & 5 \\
\hline & & & & & Potential siblings & Coder review \\
\hline & & & & & Paul Anderson & Sibling identified \\
\hline & & & & & Larry Anderson & Not sibling \\
\hline
\end{tabular}

Figure 2: A simplified example of the sibling match algorithm. For a sibling match to be identified in the data, a combatant had to have the: (i) same soundex for their last name; (ii) same soundex for their mother's name; (iii) have a Levenshtein distance of six or less for their last names and mother's name; and (iv) be from the same home state. Paul Anderson is initially matched with Aaron Anderson and Larry Anderson. In the last stage of the match, Larry Anderson is removed as a sibling because his mother's name was too dissimilar to Aaron and Larry Anderson's mother's name.

is a phonetic algorithm used to index names to identify matched people in data sets. For example, the names Johnson, Jonson, or Jahnson are assigned the phonetic value J525. Using the soundex J525, these combatants can then be matched as having the same last name even though their names are spelled differently. Soundex matching for names is frequently used to match the health records of patients who have gone to multiple hospitals (Snae 2007; Kabudula et al. 2014). The soundex function was applied to both the last names and mothers' names of the combatants. For two combatants to be identified as potential siblings in the data they had to have the same soundex for their last names and mother's name.

The team then measured the Levenshtein distance between the potential matches to reduce the pool of potential siblings. Levenshtein distance counts the character changes needed in a word so that it perfectly matches another word. For example, the name John Smith has a Levenshtein distance of two to Jon Smih because the "h" needs to be added to match "John" to "Jon" and the letter "t" needs to be deleted from Smith to Smih for the names to be perfectly matched. The potential sibling pairs were removed from the soundex match pool if their names had a greater Levenshtein distance than 6. Last, the sibling matches were then removed if the sibling pairs had a different home state. The research team then went through the remaining sibling matches and removed combatants who were still mistakenly matched through this process. In total, there are 57 siblings in the data. Among the matched siblings, the mean Levenshtein distance between the 
last names of siblings was $1.71 .^{2}$ From the sibling matches, the combatants were given a dummy variable for sibling suicide terrorist socialization if they had a sibling that volunteered to be a suicide terrorist. Figure 2 displays a simplified flow chart of the sibling match process. The dependent variable is a dichotomous variable, with (i) a soldier or administrator coded as a zero, or (ii) a suicide bomber or Inghimasi coded as a one. In total, 14 percent of Islamic State recruits requested being a suicide attacker.

\subsection{Control variables}

At the individual level, we use the following control variables to account for competing theories of terror mobilization: (i) the level of education; (ii) the previous occupations; (iii) knowledge of Sharia; (iv) familial status; and (v) age of the combatant. At the environmental level, we use the following control variables: (i) colonial history, (ii) Polity 2; and (iii) the log of GDPC of the state (Hadenius and Teorell 2007; Marshall, Gurr and Jaggers 2011; Gleditsch 2002; Teorell et al. 2015). These control variables were selected on the basis of previous theories for suicide terrorist and combatant mobilization, and criminology research on socially deviant behavior. In particular, several researchers have argued that suicide terrorists are motivated by ideational (Berrebi 2007) versus economic incentives (Krieger and Meierrieks 2011; Khashan 2003).

In the present analysis, we use a dummy variable to identify if combatants had (i) some college or more and (ii) if the combatant was previously unemployed. These variables help approximate if a combatant was better educated and wealthier relative to the other fighters. In addition to the education and unemployment variables, we also include a variable for if the Islamic State recruit identified as having an "advanced" knowledge of Sharia. This variable helps to determine whether or not a suicide fighter is motivated by religious fervor. Finally, we include a dummy variable for if the combatant is married or has children, and the age of the combatant. Sociologists have found a strong relationship between criminal behavior, age, and familial status of a person (Stolzenberg and D'Alessio 2008; Loeber and Farrington 2014). For the analysis, the age variable is normalized so that it has a mean value of zero and variance of one.

The environmental controls are also selected from extant research of suicide terrorist and combatant mobilization. Several scholars have found that combatants are mobilized by grievances based on the colonial

\footnotetext{
${ }^{2}$ In the Appendix, we explore the impact of false positive matches using permutation tests.
} 
history or lack of political rights within their state (Pape 2003, 2006; Piazza 2008). These researchers argue that terrorist organizations use suicide attacks because of grievances against the state. This effect is especially pronounced in states with a colonial history because: (i) there is often still a political presence from the former colonial power within their former colonies; and (ii) the act of colonization in itself increases grievances among the state's population. For the analysis, we use a dummy variable for colonial history if the combatant's state had been colonized or not (Wahman, Teorell and Hadenius 2013). To measure political rights, we use the Polity 2 measure, which approximates the level of democracy of a state (Marshall, Gurr and Jaggers 2011). In addition to research on grievances for combatant mobilization several studies have argued that suicide terrorists and combatants are motivated by economic incentives (Fearon and Laitin 2003; Choi 2014; Haddad 2004). We include the log of GDP per capita of the combatant's home country in the analysis to test the extent to which worse economic conditions mobilize suicide terrorists (Gleditsch 2002; Teorell et al. 2015). The Polity 2 and log of GDP per capita variables are centered and scaled so that each variable has a mean of zero and variance of one.

The alternative individual and environmental theories being tested in this paper were developed by analyzing combatant mobilization against civilian population behaviors (i.e., why someone carries out a terrorist attack against not carrying out a terrorist attack). In turn, these theories do not perfectly reflect the analytic strategy used in this paper because we are analyzing suicide terrorism mobilization conditional on being a terrorist. Notwithstanding, the modeling strategy used in this paper helps distinguish suicide terrorist mobilization from other terrorist mobilization, which is an inference problem endemic to previous research in this area (i.e., disentangling suicide versus non-suicide terrorist mobilization).

\section{Analysis}

We use two analytic approaches to test the effect of sibling socialization on suicide terrorist mobilization:

(i) a fixed effects logistic regression clustering by combatant home country; and (ii) a multilevel logistic regression which treats combatant home countries as random intercepts and includes both individual and the environmental causes for suicide terrorist mobilization. The models are validated using 10-cross folds. This 
enables us to see if the parameters of interest generalize. The fixed effects logistic regression follows:

$$
\begin{aligned}
y_{i j} & =\left\{1+\exp \left[-\beta_{0}+\beta_{1 j} X_{1 j}+\ldots \beta_{n j} X_{n j}+\alpha_{j}+\epsilon\right]\right\}^{-1} \\
\epsilon & \sim \mathcal{N}\left(0, \sigma_{i i d}^{2}\right)
\end{aligned}
$$

Where $\beta_{1}$ represents the effect of a sibling socialization on volunteering to be a suicide terrorist and $\beta_{2}$ to $\beta_{n}$ as the control variables, and $\alpha_{j}$ are the country fixed effects.

For the second model, we use a multilevel logistic regression. Through a multilevel modeling approach, we can appropriately estimate the effect of sibling socialization on suicide terrorism, while also controlling for country level effects, individual attributes (e.g., the combatant's education, familial status), and the environmental factors (e.g., polity or colonial history) of the combatant's home state. The multilevel logistic regression follows:

$$
\begin{aligned}
y_{i j} & =\left\{1+\exp \left[-\beta_{0}+Z_{j} \mu+\beta_{1 j} X_{1 j}+\ldots \beta_{n j} X_{n j}+\epsilon\right]\right\}^{-1} \\
\epsilon & \sim \mathcal{N}\left(0, \sigma^{2}\right) \\
f(y, \mu) & =f(y \mid \mu) f(\mu) \\
\mu & \sim \mathcal{N}(0, \gamma)
\end{aligned}
$$

In this, $\beta_{1}$ represents the effect of sibling suicide socialization on suicide terrorism mobilization, while $\beta_{2}$ to $\beta_{n}$ represent the fixed effects control variables, and $Z$ represents the random effects by country. The country intercepts are treated as observed outcomes from a normal distribution with a between group variance of $\gamma$. Within each group, $\epsilon$ is normally distributed with a mean of 0 and variance of $\sigma^{2}$. 


\section{$5 \quad$ Results}

Table 1: The cross validated fixed effects and multilevel logistic regression mean coefficient and standard error estimates. In both full models, the sibling suicide socialization variable is statistically significant and positive, which suggests that familial socialization contributes to higher rates of suicide terrorist mobilization.

\begin{tabular}{|c|c|c|c|}
\hline & \multicolumn{3}{|c|}{ Dependent variable: Suicide terrorist volunteer } \\
\hline & Simple model & Fixed effects & MLM \\
\hline \multicolumn{4}{|l|}{ Individual effects } \\
\hline (Intercept) & $\begin{array}{l}-1.83 \\
(0.06)\end{array}$ & $\begin{array}{l}-1.33 \\
(0.14)\end{array}$ & $\begin{array}{l}-2.07 \\
(0.21)\end{array}$ \\
\hline Sibling suicide socialization & $\begin{array}{c}2.53 \\
(0.65)\end{array}$ & $\begin{array}{c}2.33 \\
(0.68)\end{array}$ & $\begin{array}{l}2.35 \\
0.47\end{array}$ \\
\hline Age & & $\begin{array}{l}-0.04 \\
(0.08)\end{array}$ & $\begin{array}{c}-0.03 \\
(0.07)\end{array}$ \\
\hline Sharia knowledge & & $\begin{array}{l}-1.11 \\
(0.29)\end{array}$ & $\begin{array}{l}-1.14 \\
(0.30)\end{array}$ \\
\hline Familial status & & $\begin{array}{l}-0.29 \\
(0.17)\end{array}$ & $\begin{array}{c}-0.28 \\
(0.16)\end{array}$ \\
\hline Some college & & $\begin{array}{c}0.15 \\
(0.14)\end{array}$ & $\begin{array}{c}0.18 \\
(0.12)\end{array}$ \\
\hline Unemployed & & $\begin{array}{l}-0.33 \\
(0.22)\end{array}$ & $\begin{array}{c}-0.26 \\
(0.21)\end{array}$ \\
\hline Country fixed effects & & $\mathrm{Y}$ & \\
\hline Country random effects & & & $\mathrm{Y}$ \\
\hline
\end{tabular}

\section{Environmental effects}

Polity

Colonial history

$\log ($ GDP per capita)

\begin{tabular}{lccc}
\hline Cross folds & 10 & 10 & 10 \\
RMSE & 1.70 & 1.85 & 0.98 \\
PRMSE & 0.35 & 0.34 & 0.15 \\
Akaike Inf. Crit. & 2121.33 & 2073.97 & 2052.05 \\
Observations & 2,923 & 2,923 & 2,923 \\
\hline \hline
\end{tabular}

Note: Statistically significant values at 0.05 are bolded and standard errors are in parentheses. 


\section{$5.1 \quad$ Regression estimates}

Table 1 reports the mean coefficient and standard deviation estimates from the cross validated fixed and multilevel logistic regressions (see the Appendix for sensitivity analyses). Overall, the analysis provides strong support for the hypothesis that sibling socialization contributes to suicide terrorist mobilization. Across all cross validated models, the effect of sibling suicide terrorist mobilization was larger than any other parameter of interest (see Figure 3 for all individual level confidence interval estimates). Specifically, for the fixed effects regressions, combatants who had a sibling who volunteered to be a suicide terrorist were between 8.80 and 15.09 times more likely to become a suicide terrorist as well. Similarly, for the multilevel logistic regressions, combatants were between 6.23 and 46.60 times more likely to be a suicide terrorist if they had a sibling who volunteered to be a suicide terrorist, holding all else constant. Further, over 99 percent of the sibling suicide socialization bootstrap estimates are above zero (see Figure 4a).

At the individual level, if a combatant identified as having an advanced understanding of Sharia, they were over 3.03 to 3.14 times less likely to volunteer to be a suicide terrorist. This finding suggests that suicide terrorists are not motivated by religious fervor. At the environmental level, if a combatant came from a state that had a colonial history or was less democratic, then they were also more likely to volunteer to be a suicide terrorist. Indeed, fighters from states with a colonial history are 1.65 times more likely to volunteer to be a suicide terrorist and a one unit increase in Polity 2 decreasing the likelihood of volunteering to be a suicide terrorist by 1.36 times. Figure 4b displays the model based bootstrap estimates for the multilevel logistic regressions.

Notably, if a combatant had some college or was from a state with higher log of GDPC, they were more likely to volunteer to be a suicide terrorist. Conversely, if a combatant was unemployed, had a wife or children, or was older, they were less likely to volunteer to be a suicide terrorist. However, these variables were not statistically significant at the 0.05 level. Thus, the estimated true effect of these variables on suicide terror mobilization are indeterminate. This finding is particularly notable given the plethora of research on how economic incentives may mobilize combatants and suicide terrorists (Fearon and Laitin 2003; Krueger and Malečková 2003). 

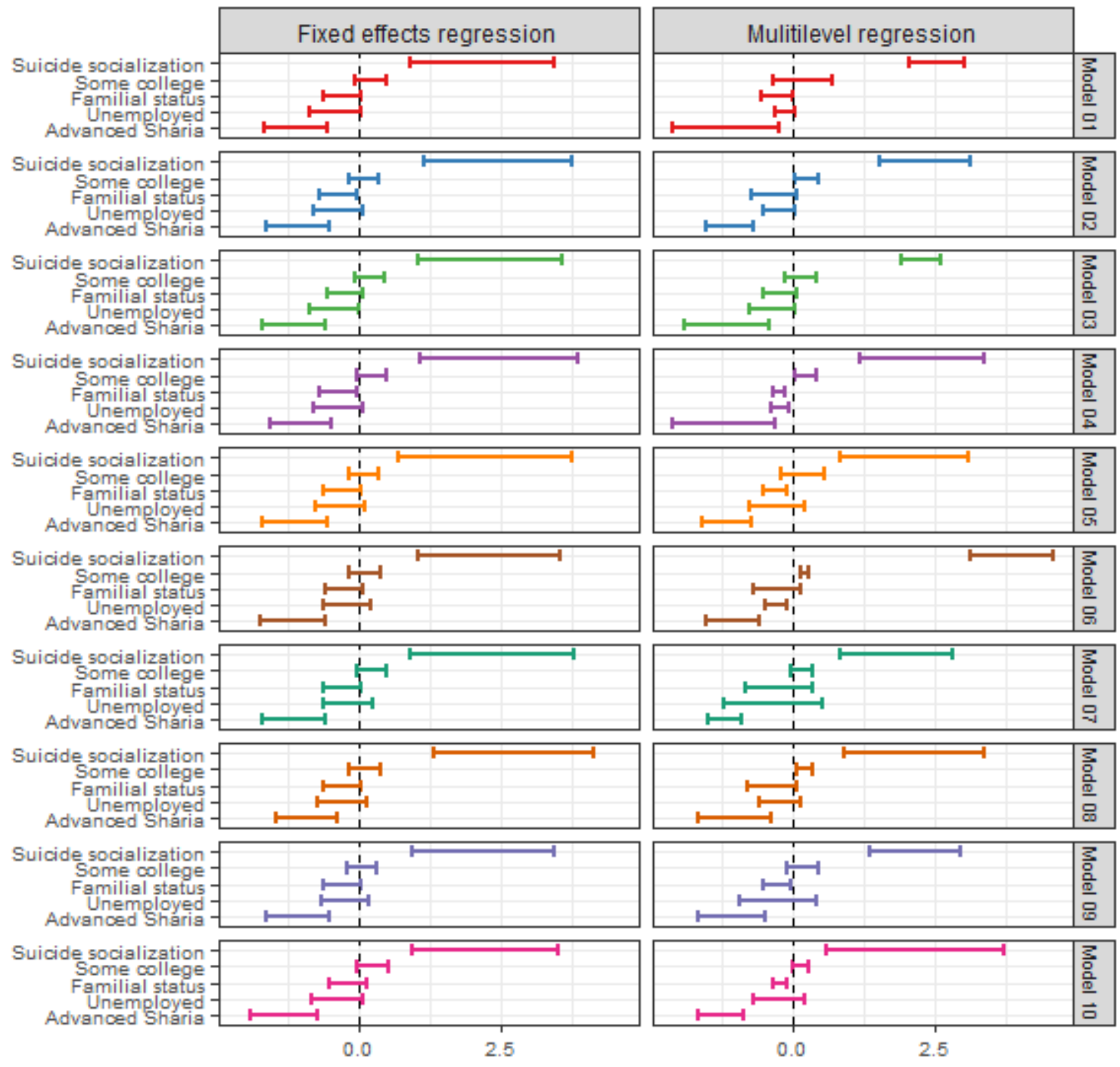

Coefficient estimates

Figure 3: 10 cross-validation estimates for the individual level effects on suicide terrorist mobilization. Across all models, the sibling socialization variable has the largest estimated effect on mobilization. 


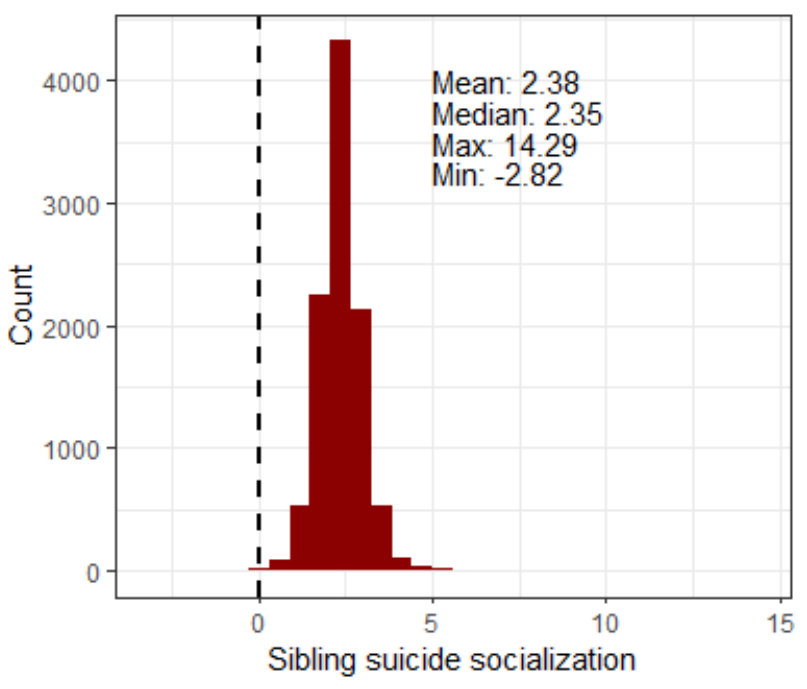

(a) Boostrap multilevel estimates.

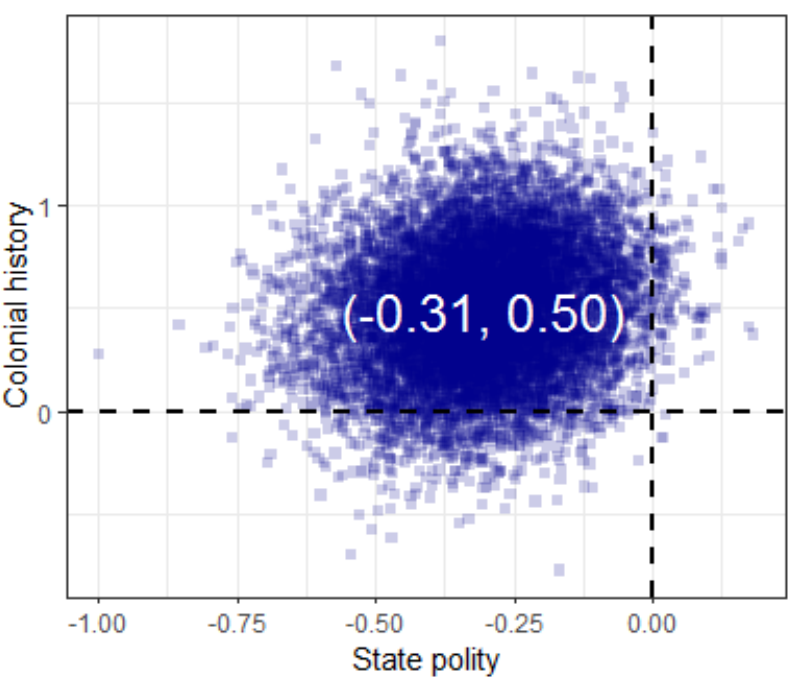

(b) Boostrap environmental estimates.

Figure 4: These figures display the multilevel model bootstrap estimates for the sibling suicide socialization, colonial history, and Polity 2. Figure (a) shows all 10,000 bootstrapped estimates across the 10 cross validated models; Figure (b) displays all colonial history and Polity 2 estimates.

\section{Discussion}

We wish to begin by noting three potential limitations posed by the data. First, according to the journalist who provided our research team with the documents, we were given the complete universe of unique Islamic State job applications. However, the data cover only the years between 2010 and 2014. These fighters may be different than the combatants who volunteered before or after the time series; particularly, in light of the United States, Turkey and Russia's more aggressive intervention into the Syrian Civil War after 2014 (Broder December 7, 2015; Yackley August 6, 2019; Roth, Murphy and Ryan September 30, 2015). Second, some estimates place Islamic State foreign fighter recruitment numbers around 30,000 (Bakker and Singleton 2016). If the 30,000 figure is correct, the presented data would constitute approximately 15 percent of the total fighters. However, there is no reason to expect these data to not be representative of Islamic State foreign combatants between 2010 and 2014. And third, the estimated effect of sibling socialization on suicide terrorism mobilization relies on a sample which excludes non-combatants. This means the estimated effects may not generalize to a non-combatant population.

In addition to some potential issues related to the data, several of the theories tested in this paper were developed through studying domestic terrorism and civil conflict, and not the differences between 
terrorist recruits. Namely, these studies use the variation on the number and places of attacks or the general populations as counterfactuals, whereas this paper compares suicide terrorist to non-suicide terrorist recruits. Thus, the previous theories on suicide terrorist mobilization discussed in this paper may not perfectly map onto data of transnational combatants.

These limitations notwithstanding, the present analysis is the first transnational, micro-analysis of suicide combatant mobilization. Through these data, we are able to precisely test several existing theories. In so doing, we find robust support for the effect of sibling socialization on suicide terrorist mobilization. In addition to the effect of sibling socialization on suicide terrorist mobilization, we also find that suicide combatants do not have an advanced understanding of Sharia and are from more autocratic states with a colonial history. The finding that Islamic State suicide recruits do not have an advanced understanding of Sharia suggests these fighters may not be motivated by religious extremism. Accordingly, state policies that target specific religious groups or teachings may be ineffective in deterring or preventing suicide terrorist attacks.

Our findings on the effect of governance and colonial history of a combatant's home country are somewhat consistent with earlier research on suicide terrorism. In particular, Pape (2003, 2006) argues that suicide terrorists are motivated by grievances related to the colonial history of their home country. In contrast to Pape's analysis, however, we find that suicide combatants are not from democratic states. Nevertheless, the fighters in this analysis traveled to Syria to carry out their attacks on behalf of the Islamic State. Therefore, they could have gone to Syria under the assumption they would eventually carry out attacks on democratic polities. Thus, this analysis supports some of Pape's conclusions on suicide terrorist mobilization. Future research should probe this issue further.

Curiously, we find no evidence that suicide terrorists are mobilized by economic incentives, education, familial status, or age, compared to other terrorists. This is particularly notable given the breadth of research on suicide terrorist mobilization, which argues that fighters are mobilized by economic incentives (Berrebi 2007; Choi 2014; Haddad 2004), ideational causes (Krueger and Malečková 2003), or social isolation (Pedahzur, Perliger and Weinberg 2003; Lankford 2013). The null findings could be related to large similarities between soldier versus suicide terrorist mobilization. Namely, these papers are often making inferences about terrorist mobilization, and using suicide terrorist events or support for suicide terrorism as their dependent 
variable.

\section{Conclusion}

Although the Islamic State has been pushed out of parts of Iraq and Syria, new organizations are likely to replace it, and terrorist and rebel activities will continue around the globe. As such, the primary question facing counterterrorism policymakers is how individual characteristics interact with environmental conditions to motivate people to carry out suicide terrorist attacks. This analysis is the first to study transnational suicide terrorism with micro-level data. Through our analysis, we find the single greatest motivation for suicide terrorist mobilization is familial socialization. Terrorism is a social phenomenon, and as such, requires a socially-oriented counterterrorism approach. In turn, demobilization efforts should be directed at preventing radicalization through the social networks of potential recruits, especially through familial ties. Demobilization efforts that target the social networks of individuals may be more impactful than previous counterterrorism approaches which sought to improve the political and economic conditions of a state, provide greater welfare to individuals, or advance anti-terrorism education initiatives. 
Abadie, Alberto. 2006. "Poverty, political freedom, and the roots of terrorism." American Economic Review $96(2): 50-56$.

Agnew, Robert. 2005. Why do criminals offend? A general theory of crime and delinquency. Roxbury Los Angeles, CA.

Asal, Victor H, R Karl Rethemeyer, Ian Anderson, Allyson Stein, Jeffrey Rizzo and Matthew Rozea. 2009. "The softest of targets: A study on terrorist target selection." Journal of Applied Security Research $4(3): 258-278$.

Ashworth, Scott, Joshua D Clinton, Adam Meirowitz and Kristopher W Ramsay. 2008. "Design, inference, and the strategic logic of suicide terrorism." American Political Science Review 102(2):269-273.

Atran, Scott. 2011. Who becomes a terrorist today? In The ethics and efficacy of the Global War on Terrorism. Springer pp. 45-58.

Bakker, Edwin and Mark Singleton. 2016. Foreign fighters in the Syria and Iraq conflict: Statistics and characteristics of a rapidly growing phenomenon. In Foreign Fighters under International Law and Beyond. Springer pp. 9-25.

Bales, Robert F and Talcot Parsons. 2014. Family: Socialization and interaction process. routledge.

Bandura, Albert and Richard H Walters. 1977. Social learning theory. Vol. 1 Prentice-hall Englewood Cliffs, NJ.

Barfi, Barak. 2016. "The military doctrine of the Islamic State and the limits of Ba'athist influence." CTC Sentinel 9(2):18-24.

Bates, Douglas, Martin Maechler, Ben Bolker, Steven Walker et al. 2014. "lme4: Linear mixed-effects models using Eigen and S4." R package version 1(7):1-23.

Bax, Mart. 1995. Medjugorje: Religion, politics, and violence in rural Bosnia. Number 16 VU University Press. 
Benmelech, Efraim, Claude Berrebi and Esteban F Klor. 2012. "Economic conditions and the quality of suicide terrorism." The Journal of Politics 74(1):113-128.

Berg, Mark T and Beth M Huebner. 2011. "Reentry and the ties that bind: An examination of social ties, employment, and recidivism." Justice Quarterly 28(2):382-410.

Berrebi, Claude. 2007. "Evidence about the link between education, poverty and terrorism among Palestinians." Peace Economics, Peace Science and Public Policy 13(1).

bin Khaled Al-Saud, Abdullah. 2019. "Saudi foreign fighters: Analysis of leaked Islamic State entry documents." King's College London: International Center for the Study of Radicalization .

Blaise, Lilia, Aurelien Breeden, Kimiko de Freytas-Tamura, Alissa Rubin, Benoit Morenne and Ceylan Yeginsu. March 24, 2016. "Ibrahim and Khalid el-Bakraoui: From bank robbers to brussels bombers." New York Times . https://www.nytimes.com/2016/03/25/world/europe/ expanding-portraits-of-brussels-bombers-ibrahim-and-khalid-el-bakraoui.html?_r=0.

Blattman, Christopher. 2009. "From violence to voting: War and political participation in Uganda." American political Science review 103(2):231-247.

Bloom, Mia. 2004. Devising a theory of suicide terror. New Jersey.

Broder, Jonathan. December 7, 2015. "Obama calls on congress to formally declare war on ISIS in oval office address." Newsweek . https://www.newsweek.com/ address-obama-vows-overcome-terrorist-threat-401796.

Burgess, Robert L and Ronald L Akers. 1966. "A differential association-reinforcement theory of criminal behavior." Social Problems 14:128.

Burke, Jason. July 9, 2005. "Who did it - and what was their motive?" The Gaurdian . https://www. theguardian.com/uk/2005/jul/10/alqaida.july71.

Callimachi, Rukmini. 2019. "Death of Hamza bin Laden Seen as Blow to al Qaeda's Future." The New York Times . https://www. nytimes.com/2019/08/01/world/middleeast/hamza-bin-laden.html. 
Campbell, Benjamin W. 2018. "Detecting Heterogeneity and Inferring Latent Roles in Longitudinal Networks." Political Analysis 26(3):292-311.

Choi, Seung-Whan. 2014. "Economic growth and terrorism: Domestic, international, and suicide." Oxford Economic Papers 67(1):157-181.

Choi, Seung-Whan and James A Piazza. 2016. "Internally displaced populations and suicide terrorism." Journal of Conflict Resolution 60(6):1008-1040.

Colas, Brandon. 2017. "What does Dabiq do? ISIS hermeneutics and organizational fractures within Dabiq magazine." Studies in Conflict \& Terrorism 40(3):173-190.

Crenshaw, Martha. 2000. "The psychology of terrorism: An agenda for the 21st century." Political psychology $21(2): 405-420$.

DeLisi, Matt, Mark T Berg and Andy Hochstetler. 2004. "Gang members, career criminals and prison violence: Further specification of the importation model of inmate behavior." Criminal Justice Studies $17(4): 369-383$.

Dull, R Thomas. 1983. "Friends' use and adult drug and drinking behavior: A further test of differential association theory." Journal of Criminal Law and Criminology 74:1608.

Edgerton, Jared F. 2019. "Suicide terrorist mobilization: Familial ties and sibling socialization." SocArXiv . doi:10.31235/osf.io/dcybm.

El Deeb, Sarah. July 4, 2018. "Islamic State says leader's son killed in Syria." AP News . https://apnews. com/59698eff72214974bc8f91ac17addbd6.

Ember, Carol R and Melvin Ember. 1994. "War, socialization, and interpersonal violence: A cross-cultural study." Journal of Conflict Resolution 38(4):620-646.

Fearon, James D and David D Laitin. 2003. "Ethnicity, insurgency, and civil war." American Political Science Review $97(1): 75-90$. 
Fujii, Lee Ann. 2004. "Transforming the moral landscape: the diffusion of a genocidal norm in Rwanda." Journal of Genocide Research 6(1):99-114.

Fujii, Lee Ann. 2008. "The power of local ties: Popular participation in the Rwandan genocide." Security Studies 17(3):568-597.

Gertz, Evelyn Ann. 2016. Is Genocidal Behavior Learned? Assessing the Familial Ties of Genocide Perpetrators $\mathrm{PhD}$ thesis The Ohio State University.

Gleditsch, Kristian Skrede. 2002. "Expanded trade and GDP data." Journal of Conflict Resolution 46(5):712724 .

Global Terrorist Database. 2018. "National Consortium for the Study of Terrorism and Responses to Terrorism (START).". https://www.start.umd.edu/gtd.

Goldstein, Harvey and Jon Rasbash. 1996. "Improved approximations for multilevel models with binary responses." Journal of the Royal Statistical Society: Series A (Statistics in Society) 159(3):505-513.

Gunaratna, Rohan. 2004. "The post-madrid face of Al Qaeda." The Washington Quarterly 27(3):91-100.

Haddad, Simon. 2004. "A comparative study of Lebanese and Palestinian perceptions of suicide bombings: The role of militant Islam and socio-economic status." International Journal of Comparative Sociology $45(5): 337-363$.

Hadenius, Axel and Jan Teorell. 2007. "Pathways from authoritarianism." Journal of Democracy 18(1):143157.

Ho, Daniel, Kosuke Imai, Gary King, Elizabeth Stuart and Alex Whitworth. 2018. "Package 'MatchIt'.".

Horgan, John. 2008. "From profiles to pathways and roots to routes: Perspectives from psychology on radicalization into terrorism." The ANNALS of the American Academy of Political and Social Science 618(1):80-94.

Jelil, Mohamed Abdel, Kartika Bhatia, Anne Brockmeyer, Quy-Toan Do and Clément Joubert. 2018. Unemployment and violent extremism: Evidence from Daesh foreign recruits. The World Bank. 
Kabudula, Chodziwadziwa W., Benjamin D. Clark, Francesc Xavier Gómez-Olivé, Stephen Tollman, Jane Menken and Georges Reniers. 2014. "The promise of record linkage for assessing the uptake of health services in resource constrained settings: A pilot study from South Africa." BMC medical research methodology $14(1): 71$.

Kalyvas, Stathis N. 2006. The logic of violence in civil war. Cambridge University Press.

Khashan, Hilal. 2003. "Collective Palestinian frustration and suicide bombings." Third World Quarterly 24(6):1049-1067.

King, Gary and Richard Nielsen. 2016. "Why propensity scores should not be used for matching." Political Analysis pp. 1-20.

Kissner, Jason and David C Pyrooz. 2009. "Self-control, differential association, and gang membership: A theoretical and empirical extension of the literature." Journal of Criminal Justice 37(5):478-487.

Krieger, Tim and Daniel Meierrieks. 2011. "What causes terrorism?" Public Choice 147(1-2):3-27.

Krueger, Alan B and Jitka Malečková. 2003. "Education, poverty and terrorism: Is there a causal connection?" Journal of Economic Perspectives 17(4):119-144.

Kruglanski, Arie W, Xiaoyan Chen, Mark Dechesne, Shira Fishman and Edward Orehek. 2009. "Fully committed: Suicide bombers' motivation and the quest for personal significance." Political Psychology $30(3): 331-357$.

Lankford, Adam. 2013. "A comparative analysis of suicide terrorists and rampage, workplace, and school shooters in the United States from 1990 to 2010." Homicide Studies 17(3):255-274.

Loeber, Rolf and David P Farrington. 2014. "Age-crime curve." Encyclopedia of Criminology and Criminal Justice pp. $12-18$.

Lupu, Noam and Leonid Peisakhin. 2017. "The legacy of political violence across generations." American Journal of Political Science 61(4):836-851. 
MacAskill, Ewen. 2016. "ISIS document leak reportedly reveals identities of 22,000 recruits." The Gaurdian

URL: https://www.theguardian.com/world/2016/mar/09/isis-document-leak-reportedly-reveals-identitiessyria-22000-fighters

Marshall, Monty G, Ted Robert Gurr and Keith Jaggers. 2011. "Center for Systemic Peace." Polity IV Project .

Matsueda, Ross L. 2006. "Differential social organization, collective action, and crime." Crime, Law and Social Change 46(1-2):3-33.

McCabe, Sean Esteban, John E Schulenberg, Lloyd D Johnston, Patrick M O'Malley, Jerald G Bachman and Deborah D Kloska. 2005. "Selection and socialization effects of fraternities and sororities on US college student substance use: a multi-cohort national longitudinal study." Addiction 100(4):512-524.

McCauley, Clark and Sophia Moskalenko. 2008. "Mechanisms of political radicalization: Pathways toward terrorism." Terrorism and political violence 20(3):415-433.

McCulloch, Charles E and John M Neuhaus. 2005. "Generalized linear mixed models." Encyclopedia of Biostatistics 4 .

Merari, Ariel. 2010. Driven to death: Psychological and social aspects of suicide terrorism. Oxford University Press.

Okafor, Godwin and Jenifer Piesse. 2018. "Empirical investigation into the determinants of terrorism: Evidence from fragile states." Defence and Peace Economics 29(6):697-711.

Omar, Ammar Cheikh and Richard Engel. 2018. "Meet the ISIS Defector Who Handed Over Stolen Personnel Files." NBC News. https://www.nbcnews.com/storyline/isis-uncovered/ how-we-obtained-thousands-secret-personnel-files-stolen-isis-n557306.

Pape, Robert A. 2003. "The strategic logic of suicide terrorism." American Political Science Review 97(3):343361. 
Pape, Robert Anthony. 2006. Dying to win: The strategic logic of suicide terrorism. Random House Incorporated.

Pedahzur, Ami, Arie Perliger and Leonard Weinberg. 2003. "Altruism and fatalism: The characteristics of Palestinian suicide terrorists." Deviant Behavior 24(4):405-423.

Piazza, James A. 2006. "Rooted in poverty?: Terrorism, poor economic development, and social cleavages." Terrorism and political Violence 18(1):159-177.

Piazza, James A. 2008. "A supply-side view of suicide terrorism: A cross-national study." The Journal of Politics 70(1):28-39.

Rosenbaum, Alan and K Daniel O'Leary. 1981. "Children: The unintended victims of marital violence." American Journal of Orthopsychiatry 51(4):692.

Roth, Andrew, Brian Murphy and Missy Ryan. September 30, 2015. "Russia begins airstrikes in Syria; U.S. warns of new concerns in conflict." Washington Post. https://www.washingtonpost.com/ world/russias-legislature-authorizes-putin-to-use-military-force-in-syria/2015/09/30/ f069f752-6749-11e5-9ef3-fde182507eac_story.html.

Rüegger, Seraina. 2019. "Refugees, ethnic power relations, and civil conflict in the country of asylum." Journal of Peace Research 56(1):42-57.

Schwartz, Seth J, Curtis S Dunkel and Alan S Waterman. 2009. "Terrorism: An identity theory perspective." Studies in Conflict \& Terrorism 32(6):537-559.

Snae, Chakkrit. 2007. "A comparison and analysis of name matching algorithms." International Journal of Applied Science. Engineering and Technology 4(1):252-257.

Spier, Troy E. 2018. "Extremist propaganda and Qur'anic scripture: A 'radical' corpus-based study of the Dabiq." Discourse \&3 Society 29(5):553-567.

Stammers, Tom. 2017. Ordinary men: Reserve Police Battalion 101 and the final solution in Poland. Macat Library. 
Stekhoven, Daniel J. 2011. "Using the missForest package." $R$ package pp. 1-11.

Stolzenberg, Lisa and Stewart J D'Alessio. 2008. "Co-offending and the age-crime curve." Journal of Research in Crime and Delinquency 45(1):65-86.

Stretesky, Paul B and Mark R Pogrebin. 2007. "Gang-related gun violence: Socialization, identity, and self." Journal of Contemporary Ethnography 36(1):85-114.

Sutherland, Edwin H and Donald R Cressey. 1978. Criminology. Toronto: JB Lippincott Company.

Temple-Raston, Dina. March 13, 2016. "ISIS attracts ex-cons, creating a new brand of Jihadist." NPR . $\quad$ https://www.npr.org/sections/parallels/2016/03/31/472576873/ isis-attracts-ex-cons-creating-a-new-brand-of-jihadist.

Teorell, Jan, Stefan Dahlberg, Sören Holmberg, Bo Rothstein, Anna Khomenko and Richard Svensson. 2015. "The quality of government standard dataset." University of Gothenburg: The Quality of Government Institute.

Van der Leeden, Rien, Erik Meijer and Frank MTA Busing. 2008. Resampling multilevel models. In Handbook of multilevel analysis. Springer pp. 401-433.

Vinograd, Cassandra and Annick M'Kele. 2016. "Belgium Charges Two Men in Relation to Brussels Terror Attacks." NBC News. https://www.nbcnews.com/storyline/brussels-attacks/ belgium-charges-two-men-relation-brussels-terror-attacks-n554516.

Wahman, Michael, Jan Teorell and Axel Hadenius. 2013. "Authoritarian regime types revisited: updated data in comparative perspective." Contemporary Politics 19(1):19-34.

Wood, Elisabeth Jean and Wood Elisabeth Jean. 2003. Insurgent collective action and civil war in El Salvador. Cambridge University Press.

Yackley, Ayla Jean. August 6, 2019. "US warns Turkey on Syria amid last-ditch talks to resolve buffer zone dispute." Al-Minitor . url = https://www.al-monitor.com/pulse/originals/2019/08/us-warns-turkey-syriabuffer-zone.html. 
Yardley, Jim, Rukmini Callimachi and Scott Shane. March 24, 2016. "Brussels attacks: Why are so many terrorists brothers?" The Irish Times. https://www.irishtimes.com/news/world/europe/ brussels-attacks-why-are-so-many-terrorists-brothers-1.2585730.

Zenn, Jacob. 2014. "Leadership Analysis of Boko Haram and Ansaru in Nigeria." CTC Sentinel 7(2):23-29. 


\title{
Suicide terrorist mobilization: Familial ties and sibling socialization
}

\section{Appendix}

\author{
Anonymized authors
}

October 1, 2019

\section{Contents}

Previous research has attributed the motivations of suicide terrorists to religious fervor, political engagement, and organizational strategic goals, among others. The motivations of suicide terrorists, however, are often related to local and familial dynamics; specifically, combatants' primary socialization on norms related to violence. To better understand suicide terrorism, we use a data set of 2,923 individual fighter-level observations of combatants for the Islamic State. These data include individual demographic data and the fighter's role for the Islamic State; including if they volunteered to be a suicide fighter. Through these data we test several extant theories of suicide terrorist mobilization (i.e., ideational or economic incentives) compared to the effect of primary socialization. We find that combatants who have a sibling that volunteered to be a suicide terrorist are approximately 10 times more likely to volunteer to be a suicide fighter. This was the largest effect on mobilization compared to other theories. 
Table of contents 


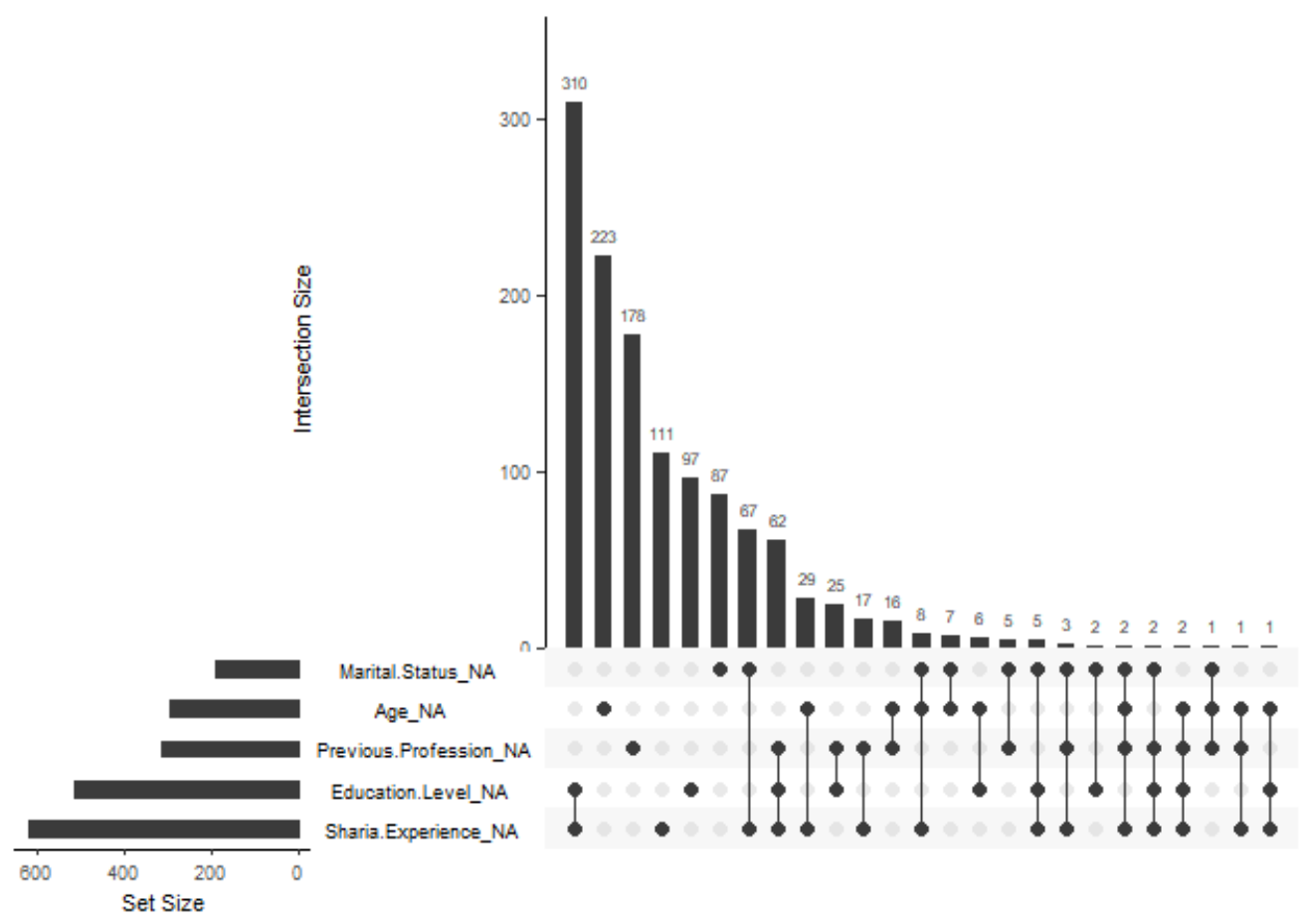

Figure 5: Cross tabulations of the missing data from the Islamic State job applications. In total, there are 223 applications missing the knowledge of Sharia and education variables and 67 applications missing the knowledge of Sharia and marital status variable.

\section{Appendix}

\section{Data}

\subsection{Data cleaning}

Among the 2,923 applications, the Knowledge of Sharia variable is missing in 21 percent of applications, the level of education is missing in 17 percent of applications, previous profession is missing in 10 percent of applications, age of the combatant is missing for 10 percent of the applications, and marital status is missing in 6 percent of the applications. Figure 5 displays cross tabulations of the missing data from the Islamic State applications. For the analysis, the missing variables are imputed using random forest, with an estimated out-of-bag normalized root mean square error (NRMSE) of 0.08 (Stekhoven 2011). The low NRMSE suggests the imputed values are highly accurate. Table 2 displays summary statistics of the cleaned data. 
Table 2: Summary statistics for the independent and dependent variables.

\begin{tabular}{rcccccc}
\hline & Mean & Median & Min & First quantile & Third quantile & Max \\
\hline Suicide volunteer & 0.14 & 0.00 & 0.00 & 0.00 & 0.00 & 1.00 \\
Sibling suicide socialization & 0.01 & 0.00 & 0.00 & 0.00 & 0.00 & 1.00 \\
Age & -0.01 & -0.14 & -2.10 & -0.59 & 0.46 & 5.90 \\
Sharia knowledge & 0.08 & 0.00 & 0.00 & 0.00 & 0.00 & 1.00 \\
Familial status & 0.32 & 0.00 & 0.00 & 0.00 & 1.00 & 1.00 \\
Some college & 0.30 & 0.00 & 0.00 & 0.00 & 1.00 & 1.00 \\
Unemployed & 0.08 & 0.00 & 0.00 & 0.00 & 0.00 & 1.00 \\
Polity 2 & 0.04 & -0.16 & -1.09 & -0.63 & 1.07 & 2.00 \\
Colonial history & 0.54 & 0.00 & 0.00 & 1.00 & 1.00 & 1.00 \\
$\log$ (GPD per capita) & 0.01 & -0.25 & -2.74 & -0.83 & 0.98 & 3.10 \\
\hline
\end{tabular}

\section{Analysis}

\subsection{Multilevel logistic regression}

This modeling approach addresses both atomistic and ecological fallacies that relate to treating the observed outcome as a product of both individual and environmental characteristics. If we simply assign environmental variables to individual observations, we can estimate the individual effects by pooling the standard error, however, this violates the assumption of independence between the experimental units. For multilevel models, $\hat{\beta}$ and $\hat{\mu}$ are the best unbiased linear predictors for $\beta$ and $\mu$. The values are derived through the Henderson mixed model equation:

$$
\left(\begin{array}{c}
X^{\prime} \frac{1}{\sigma^{2}} y \\
Z^{\prime} \frac{1}{\sigma^{2}} y
\end{array}\right)=\left(\begin{array}{cc}
X^{\prime} \frac{1}{\sigma^{2}} X & X^{\prime} \frac{1}{\sigma^{2}} Z \\
Z^{\prime} \frac{1}{\sigma^{2}} X & Z^{\prime} \frac{1}{\sigma^{2}} Z+\frac{1}{\gamma}
\end{array}\right)\left(\begin{array}{l}
\hat{\beta} \\
\hat{\mu}
\end{array}\right)
$$

Because the conditional variance is unknown, the independent variables and the variance is jointly estimated using an expectation-maximization (EM) algorithm. The EM algorithm iteratively calculates the maximum likelihood of the predictors and treats the between and within group variance as unknown nuisance parameters (McCulloch and Neuhaus 2005; Bates et al. 2014; Campbell 2018). The independent variables for the multilevel models are estimated with 1,000 parametric, or model based, bootstraps for each cross validated model. Model based bootstrapping resamples the data based on the observed parameter estimates. This approach is particularly useful for multilevel models because it maintains the hierarchical structure of the data, whereas if researchers resampled the observed outcomes through non-parametric bootstrapping 


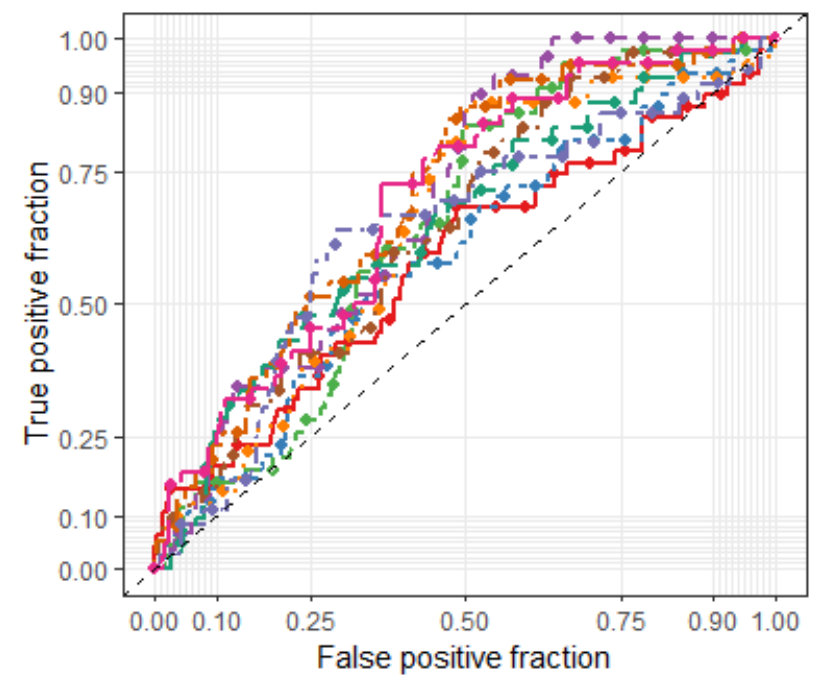

(a) ROC curve for FE regressions.

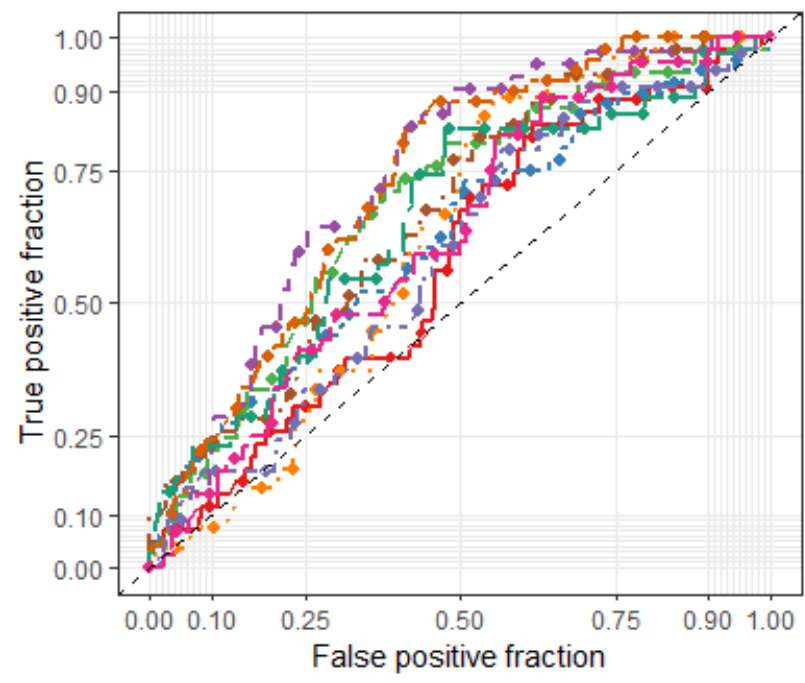

(b) ROC curve for MLM regressions.

Figure 6: These figures display the fixed effects and multilevel model logistic regression ROC curves for the cross validated models. The out of sample prediction is approximately 86 percent.

may drastically change the hierarchical structure of the data (Goldstein and Rasbash 1996; Van der Leeden, Meijer and Busing 2008).

\section{Results}

\subsection{Prediction}

Figures 6a and b display the Receiver Operating Characteristic (ROC) curves (the rate of true and false positives) for the cross validated multilevel and fixed effects logistic regressions. In total, these models both have an overall accuracy of 86 percent, but limited accuracy for detecting true positive values in the test data (i.e., correctly classifying the suicide terrorists). However, when the sibling suicide socialization variable is excluded in the fixed effects model, the overall precision of the model decreases by 2 percent. This is the largest decrease in accuracy for the removal of any of the individual and environmental parameters of interest, which suggests that sibling socialization has the largest effect on mobilization among the parameters of interest. 


\section{Sensitivity analysis}

To test the effect of sibling suicide socialization on suicide terrorist mobilization, we perform two sensitivity checks: (i) genetically matching the data to increase the balance on observable variables; and (ii) performing a quasi-permutation test on the sibling suicide socialization variable. Specifically, the data is genetically matched on the sibling suicide socialization variable using the combatant's age, knowledge of Sharia, familial status, if they had some college, were unemployed, and their state's polity, colonial history, and log of GDPC. This increased the balance of across all variables in the data (King and Nielsen 2016; Ho et al. 2018). For the permutation test, we resampled the sibling suicide socialization variable by matching new sibling pairs randomly with another combatant from their home country. The permutation test serves two purposes. First, it helps us better understand the observed treatment effect. Namely, we can approximate an empirical distribution of potential outcomes. Second, this process helps us better understand the impact of measurement error (i.e., accidentally matching siblings in the data who are actually unrelated).

\section{$12.1 \quad$ Matching}

In the treated matched data, 67 percent of combatants volunteered to be suicide terrorists, while 33 percent wanted to be soldiers; whereas in the untreated data only 15 percent of the combatants wanted to be suicide terrorists and 85 percent volunteered to be soldiers. Using the matched data, we perform three statistical tests on the effect of sibling socialization on suicide terrorist mobilization: (i) difference in proportion $\chi^{2}$ test; (ii) difference in proportion $z$-test; and (iii) a Kolmogorov-Smirnov (KS) test for a difference in distributions. The $\chi^{2}$ and KS tests are non-parametric models, which adds additional robustness to the presented findings. Figure 7a displays the proportion of suicide and non-suicide terrorist in the matched data. Across all three models, the $p$-value is less than 0.05 . These findings add additional support that sibling socialization contributes to suicide terrorist mobilization. 


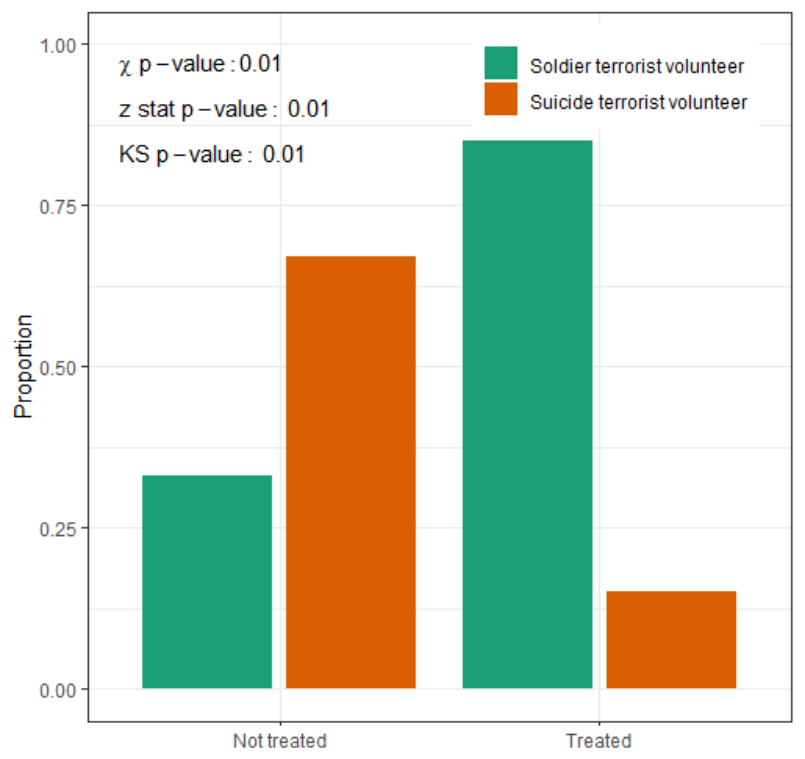

(a) Matched data proportions.

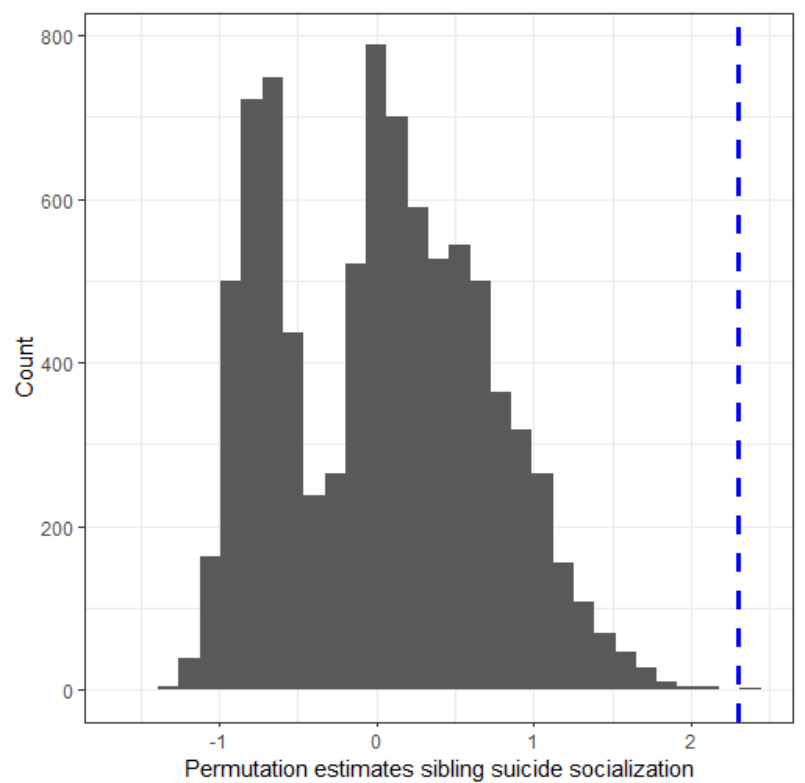

(b) Quasi-permutation estimates.

Figure 7: Figure (a) displays the proportion of the treated and untreated data on the matched sibling suicide socialization mechanism. The $p$-values for the difference in proportion and distribution are less than 0.05 . Figure (b) displays an approximated distribution for the treatment effect of the sibling suicide socialization variable. The blue line signifies the observed treatment effect. Across 10,000 simulation the observed value of 2.33 is larger than 99 percent of the permutation values.

\subsection{Permutations}

We perform 10,000 permutation estimates by resampling the sibling suicide socialization variable and holding all other variables constant. Over 99 percent of estimated permutation treatment effects are less than the observed treatment effect of 2.33 (see Figure 7b for the observed empirical distribution). Moreover, 53 percent of permutation estimates were negative. This suggests that measurement error (i.e., false positive sibling matches) decreases the observed treatment effect of the sibling suicide socialization variable. 